\title{
The usefulness of infrared spectroscopy in examinations of adhesive tapes for forensic purposes
}

\author{
Janina Zięba-Palus* \\ Institute of Forensic Research, Westerplatte 9, 31-033, Krakow, Poland
}

\begin{abstract}
Infrared spectroscopy was applied in examination and comparative analysis of adhesive tapes. By providing information about the polymer composition, it enables classification of both backings and adhesives into defined chemical classes. It was found that samples of the same type and similar infrared spectra can be differentiated sometimes based only on the presence of peaks of very low intensity originating from minor components. The results demonstrated that infrared spectroscopy appears to be a valuable analytical technique for discriminating between samples of adhesive tapes for forensic purposes.
\end{abstract}

\section{Introduction}

Tape fragments are found at various crime scenes. Electrical tapes can be used in the process of wiring electronic devices to bombs, duct tapes to bind victims of violent crimes, and other tapes to wrap packages containing drugs, explosives or other threatening materials. Frequently, forensic scientists are requested to compare fragments of a tape encountered at a crime scene with fragments originated from a suspect in order to establish whether they could come from the same roll (have a common origin). Visual investigations performed currently provide information about physical fit, tape width, colour and morphology [1]. Infrared spectroscopy (FT-IR) and pyrolysis gas chromatography (Py-GC-MS) enable characterisation of organic compounds in the backing layer and adhesive layer of the tape [2-4] and Inductively Coupled Plasma Mass Spectrometry (ICP/MS) points to their elemental composition $[5,6]$ as well as X-ray fluorescence spectroscopy (XRF) [7].

The discriminating power of these methods is limited, however. FT-IR is used mainly to determine the class of adhesive and backing material used [8-10]. More information about organic compounds like polymers and additives can be obtained using Py-GC/MS $[11,12]$.

A combination of FT-IR with visual comparison and elemental analysis enables discrimination between different brands of tapes but generally cannot be used for further discrimination between different batches of one brand of tape [10].

Some authors have found that application of High Resolution Inductively Coupled Plasma Mass Spectrometry (HR ICP-MS) enables determination of profiles of trace elements present in the tapes and could help in differentiation between different batches of the same type of tape $[5,6]$.

As a non-destructive method, infrared spectroscopy is routinely applied in forensic examination of different polymer samples. Being sensitive to molecular structure, it provides valuable information about the chemical composition of such materials as paints, plastics and glues [13-16]. The information obtained is in many cases sufficient for classification of these materials. Some authors recommend application of attenuated total reflection technique (ATR) in examination and comparison of polymer samples $[8,9]$.

In this article, the focus will be on the potential of FT-IR in discrimination of adhesive types. Chemical functional group analysis of backing and adhesive, i.e. polymer components of tapes, carried out by infrared spectroscopy may help in distinguishing between different tapes. It will be demonstrated that this method offers a major step forward in forensic tape investigations by determining polymers and additives in both backings and adhesives of tapes.

Generally, tapes consist of a backing film and an adhesive layer. The backing film is primed with a primer layer for improved adherence of the adhesive layer to the backing film. A release coating is applied on the back side of the backing film. During unwinding of the tape roll, this coating assists in reducing unwind tension and preventing adhesives from the tape from sticking to the back side of the tape beneath it. So, the tape is usually structured as follows (starting at the back of the tape): release coating/backing film/primer layer/adhesive layer. In principle, all these separate layers can be investigated. In practice, however, it is difficult to isolate very thin primer layer as well as release coating. In this study, the tape was divided into two layers only, i.e. backing and adhesive (glue) and both layers were investigated separately.

\section{Materials and methods}

Both the glue and the backing of 50 adhesive tapes of various kinds (packaging tape, duct tape, insulation tape) (Table 1) were examined by the use of infrared spectrometry. All tapes were purchased from supermarkets and stores at different times.

Infrared measurements were performed using an FTS 40Pro Fourier-transform infrared spectrometer (BioRad/Digilab), which

Correspondence to: Janina Zięba-Palus, Institute of Forensic Research, Westerplatte 9, 31-033, Krakow, Poland, E-mail: jzieba@ies.krakow.pl

Key words: forensic identification, adhesive tapes, FTIR, discrimination

Received: February 08, 2017; Accepted: March 04, 2017; Published: March 07, 2017 
Table 1. Examined tapes.

\begin{tabular}{|c|c|c|c|c|c|}
\hline No. & Tape & Colour & No. & Tape & Colour \\
\hline 1 & Prefecta & colourless & 26 & Tesaflex 53947 & black \\
\hline 2 & Painto & grey & 27 & Tesa perfect & green \\
\hline 3 & Advance AT169 & red & 28 & Grand & colourless \\
\hline 4 & Advance AT175 & green & 29 & Grand & white \\
\hline 5 & Advance AT4 & brown & 30 & Scotch 508 & colourless \\
\hline 6 & Advance AT6152 & white & 31 & Scotch magic 810 & white \\
\hline 7 & Advance AT30 & colourless & 32 & Scotch 550 & colourless \\
\hline 8 & Advance AT6102 & black & 33 & Scotch Crystal 600 & colourless \\
\hline 9 & Advance AT272 & silver & 34 & Scotch Removable 811 & white \\
\hline 10 & Advance AT202 & yellow & 35 & Stick'n & white \\
\hline 11 & Bizon & green & 36 & Scotch & colourless \\
\hline 12 & Global System & colourless & 37 & Scley 914 & black-yellow \\
\hline 13 & Global System & grey & 38 & Goldtape & grey \\
\hline 14 & Lobos & colourless & 39 & Goldtape & brown \\
\hline 15 & Herlitz & colourless & 40 & Goldtape & yellow \\
\hline 16 & Tesco & brown & 41 & Tape International & yellow \\
\hline 17 & Tesco & colourless & 42 & Global point & yellow \\
\hline 18 & Tesa- Fixing & white & 43 & Dalpo & grey \\
\hline 19 & - & red-white & 44 & K2 & grey \\
\hline 20 & Blue delphin tapes & yellow & 45 & Diall & colourless \\
\hline 21 & Blue delphin tapes & yellow & 46 & Tape International & yellow \\
\hline 22 & Blue delphin tapes & grey & 47 & Purs & black \\
\hline 23 & Tesa signal & red-white & 48 & Euro-tape silent & colourless \\
\hline 24 & Tesaflex 53947 & blue & 49 & Euro-tape silent & brown \\
\hline 25 & Tesco & colourless & 50 & Euro-tape & yellow \\
\hline
\end{tabular}

was equipped with a water-cooled high temperature ceramic source (MIR) and coupled with a UMA 500 microscope equipped with an MCT detector. IR spectra in the mid-infrared range were recorded at a resolution of $4 \mathrm{~cm}^{-1}$. Each spectrum represented a collection of 512 scans. The samples were placed on the microscope stage of the spectrometer and measured by the transmission technique in the infrared beam. Glues were scraped from the backing and put directly on the $\mathrm{KBr}$ plate. Backings, after removing the glue and cleaning with appropriate solvent, were cut into thin slices using a scalpel. There were collected from each tape 3 samples of both backing and glue and then examined three times in the same conditions.

\section{Results and discussion}

On the basis of obtained IR spectra, tapes were divided into several groups that differed in terms of backing and adhesive content (Table 2). Each group was named on the basis of the main polymer present in the sample. Spectra were compared visually, taking into account the number, location and intensity of particular absorption bands.

\section{Backing}

Backing materials were divided into 4 groups - namely, polypropylene, polyethylene, cellulose and polyester backings. The backings of 3 of the studied tapes could not be classified into any of the above groups on the basis of the obtained IR spectra. However, these spectra differed significantly from each other and from the remaining spectra. Furthermore, in one of the tapes the backing was aluminium foil.

The largest number of samples were classified into the group of polypropylene backings. In the IR spectra of polypropylene backings,
Table 2. Grouping of examined samples on the basis of their infrared spectra.

\begin{tabular}{|c|c|c|c|c|}
\hline \multirow{7}{*}{ 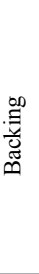 } & Type & Group & Number of samples & Differentiated samples \\
\hline & A & Polypropylene & 20 & 0 \\
\hline & B & Polyethylene & 17 & 6 \\
\hline & $\mathrm{C}$ & Polyester & 6 & 4 \\
\hline & $\mathrm{D}$ & Acetylated cellulose & 3 & 0 \\
\hline & & Single spectra & 3 & 3 \\
\hline & & Aluminum & 1 & 1 \\
\hline \multirow{5}{*}{$\frac{Ð}{0}$} & K & Rubber with styrene & 15 & 6 \\
\hline & $\mathrm{L}$ & Polyester & 4 & 2 \\
\hline & M & Butadiene-styrene & 4 & 2 \\
\hline & $\mathrm{N}$ & Acryl & 25 & 9 \\
\hline & & Non identified & 2 & 2 \\
\hline
\end{tabular}

only absorption bands originating from vibrations of $\mathrm{C}-\mathrm{H}, \mathrm{CH}_{2}$ and $\mathrm{CH}_{3}$ groups in the polymer chain were visible (Figure 1a). That is why backings from tapes belonging to this group could not be differentiated from each other on the basis of their IR spectra (Table 3).

However, spectra of polyethylene backings differed from each other significantly. Some of the obtained spectra contained - apart from bands originating from vibrations of $\mathrm{C}-\mathrm{H}$ and $\mathrm{CH}_{2}$ functional groups in the polymer (Figure $1 \mathrm{~b}$ ) - bands originating from additives for improving the quality of the tape, such as carbonates, ionomers or vinyl acetate (Figure 2- labelled with arrows). On the basis of IR spectra, it was possible to distinguish 6 tapes with different spectra and thus (different) chemical composition from the remainder belonging to this group.

In the group of polyester backings, two subgroups were 


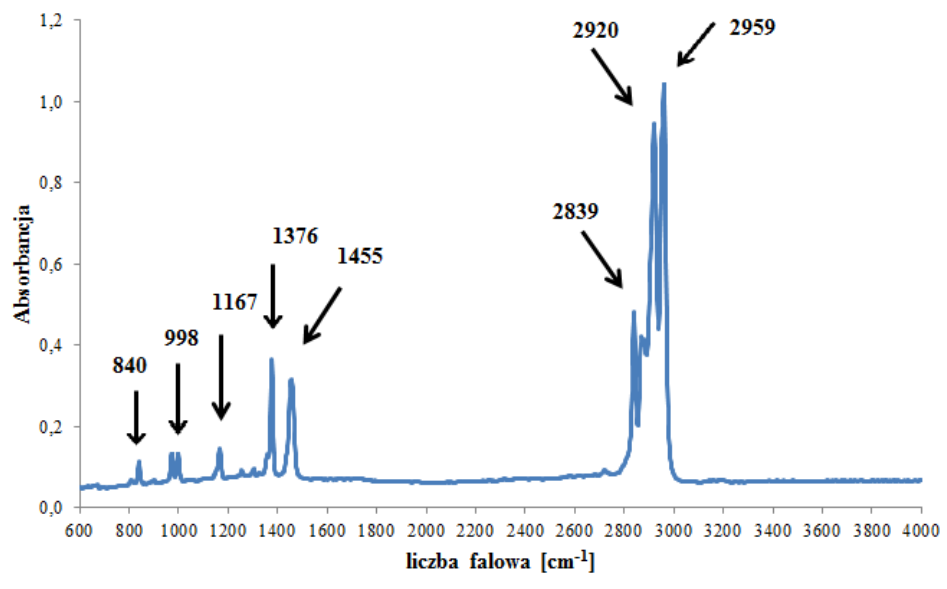

Figure 1a. Infrared spectrum of polypropylene backing.

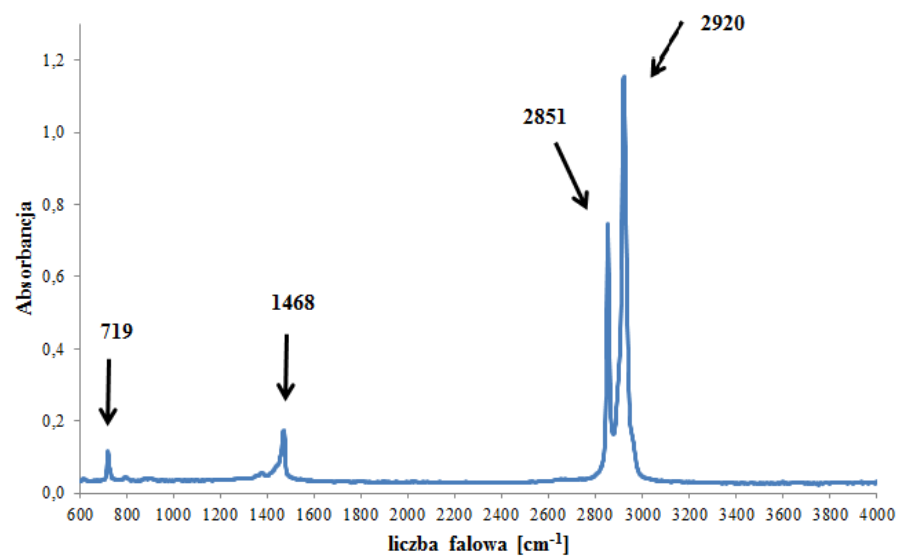

Figure 1b. Infrared spectrum of polyethylene backing.

Table 3. Characteristic absorption bands of polymers visible in IR spectra of backings.

\begin{tabular}{|c|c|c|c|}
\hline Chemical compound & Absorption band & Assignment & Numer of samples \\
\hline \multirow{3}{*}{ polypropylene } & $\left.\begin{array}{c}842 \mathrm{~cm}^{-1} \\
998 \mathrm{~cm}^{-1} \\
1167 \mathrm{~cm}^{-1}\end{array}\right\}$ & vibrations characteristic for isotactic polypropylene & \multirow[t]{2}{*}{20} \\
\hline & $1377 \mathrm{~cm}^{-1}$ & $\mathrm{C}-\mathrm{H}$ symmetric deformation vibrations & \\
\hline & $1460 \mathrm{~cm}^{-1}$ & C-H asymmetric deformation vibrations & \\
\hline \multirow{4}{*}{ polyethylene } & $720 \mathrm{~cm}^{-1}$ & $\mathrm{CH}_{2}$ rocking vibration & \multirow{4}{*}{17} \\
\hline & $1460 \mathrm{~cm}^{-1}$ & $\mathrm{CH}_{2}$ scissoring vibration & \\
\hline & $2850 \mathrm{~cm}^{-1}$ & C-H symmetrical stretching vibration & \\
\hline & $2920 \mathrm{~cm}^{-1}$ & $\mathrm{C}-\mathrm{H}$ asymmetrical stretching vibration & \\
\hline \multirow{6}{*}{$\begin{array}{l}\text { polyester } \\
\text { type C1 }\end{array}$} & $845 \mathrm{~cm}^{-1}$ & $\mathrm{CH}_{2}$ wagging vibrations & \multirow{6}{*}{2} \\
\hline & $970 \mathrm{~cm}^{-1}$ & C-O stretching vibrations & \\
\hline & $1126 \mathrm{~cm}^{-1}$ & C-O-C asymmetric stretching vibration & \\
\hline & $1252 \mathrm{~cm}^{-1}$ & $=\mathrm{C}-\mathrm{O}-\mathrm{C}, \mathrm{Ar}-\mathrm{O}-\mathrm{C}$ asymmetric stretching vibration & \\
\hline & $1340 \mathrm{~cm}^{-1}$ & $\mathrm{CH}_{2}$ wagging vibrations & \\
\hline & $1718 \mathrm{~cm}^{-1}$ & $\mathrm{C}=\mathrm{O}$ stretching vibrations & \\
\hline \multirow{5}{*}{$\begin{array}{l}\text { polyester } \\
\text { type C2 }\end{array}$} & $745 \mathrm{~cm}^{-1}$ & stretching vibrations from the aromatic ring & \multirow{5}{*}{4} \\
\hline & $1077 \mathrm{~cm}^{-1}$ & stretching vibrations $\mathrm{C}-\mathrm{O}$ in $\mathrm{O}-\mathrm{CH}_{2}$ & \\
\hline & $\begin{array}{l}1125 \mathrm{~cm}^{-1} \\
1285 \mathrm{~cm}^{-1}\end{array}$ & stretching vibrations C-O-C & \\
\hline & & stretching vibrations $\mathrm{C}-\mathrm{O}$ in $-\mathrm{O}-\mathrm{C}=\mathrm{O}$ & \\
\hline & $1726 \mathrm{~cm}^{-1}$ & stretching vibrations $\mathrm{C}=\mathrm{O}$ & \\
\hline \multirow{5}{*}{ acetylcellulose } & $1050 \mathrm{~cm}^{-1}$ & stretching vibrations $\mathrm{C}-\mathrm{O}$ & \multirow{5}{*}{3} \\
\hline & $1237 \mathrm{~cm}^{-1}$ & stretching vibrations $\mathrm{C}-\mathrm{O}-\mathrm{C}$ & \\
\hline & $1370 \mathrm{~cm}^{-1}-$ & deformation vibrations $\mathrm{CH}_{2}$ & \\
\hline & $1744 \mathrm{~cm}^{-1}$ & stretching vibrations $\mathrm{C}=\mathrm{O}$ & \\
\hline & $\sim 3400 \mathrm{~cm}^{-1}$ & stretching vibrations $\mathrm{O}-\mathrm{H}$ & \\
\hline
\end{tabular}




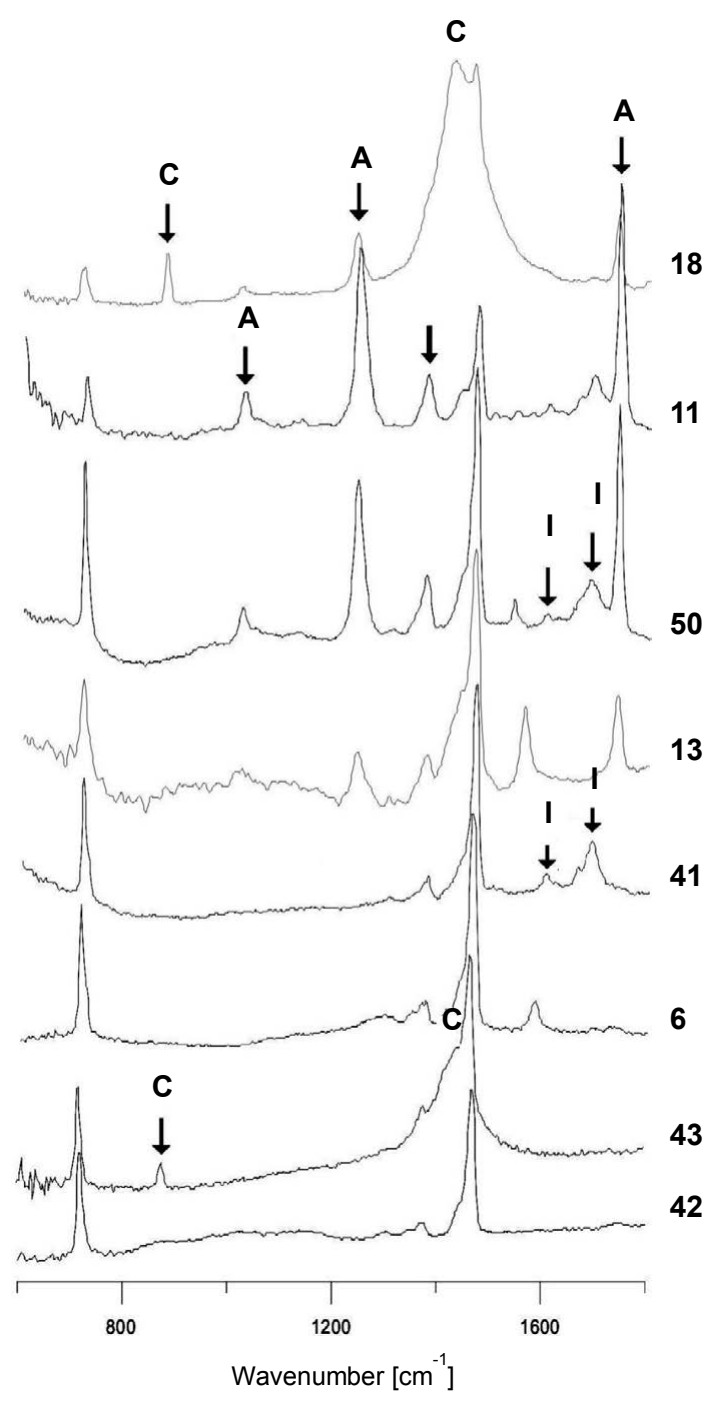

Figure 2. Comparison of infrared spectra of different polyethylene backings C-carbonates, I-ionomers, A- polyvinyl acetate. distinguished that differed in terms of the type of polyester forming the polymer network, i.e., a (sub)group of backings (C1) containing polyethylene terephthalate (Figure 3a), and a (sub)group of backings (C2) containing other esters (Figure 3b). In the spectra of backings in group $\mathrm{C} 1$ - apart from absorption bands originating from vibrations of $\mathrm{C}-\mathrm{O}-\mathrm{C}, \mathrm{C}-\mathrm{O}, \mathrm{C}=\mathrm{O}$ and $\mathrm{C}-\mathrm{H}$ groups in esters - bands originating from vibrations of $\mathrm{C}-\mathrm{H}$ groups in substituted aromatic rings were visible (Figure 3a), which were constituents of additives. Two tapes were classified into this group. Bands of the main polymer were visible in the spectra of the backings in group C2 (Figure $3 \mathrm{~b}$ - indicated by arrows) as well as bands originating from carbonate type fillers: 875 and $1420 \mathrm{~cm}^{-1}$. Small differences in obtained spectra were also observed, concerning the ratio of the intensity of band 875 (carbonates band) to band 1070 $\mathrm{cm}^{-1}$ (ester groups band). The observed differences in spectra allowed us to differentiate 4 out of the 6 samples belonging to this group.

Cellulose backings were characterised by very similar infrared spectra dominated by bands originating from vibrations of groups $\mathrm{C}-\mathrm{O}$, $\mathrm{C}-\mathrm{O}-\mathrm{C}, \mathrm{C}=\mathrm{O}$ and $\mathrm{O}-\mathrm{H}$ of cellulose (Figure 4 ).

Additionally, weak bands originating from plasticizers (o-phthalates) were present on spectra, i.e., bands at 748, 1580 and 1601 $\mathrm{cm}^{-1}$. Three tapes with infrared spectra that did not differ from each other were classified into this group.

\section{Adhesives}

Four main groups of adhesives were differentiated on the basis of the main polymer component - namely adhesives produced on the basis of natural isoprene rubber, styrene-butadiene rubber, esters and acrylates. Only IR spectra of two adhesives did not allow classification into the mentioned groups.

Most frequently, layers of adhesive present in studied tapes were produced on a base of isoprene rubber and acrylates (Table 4).

In the group of adhesives containing rubber on the basis of isoprene (Figure 5a), strong absorption bands originating from cis-1,4-isoprene were visible, as well as weak additional bands, i.e. indicating styrene, carbonates, titanium dioxide, kaolin and compounds containing a carbonyl group (Figure 5b). These differences in chemical composition

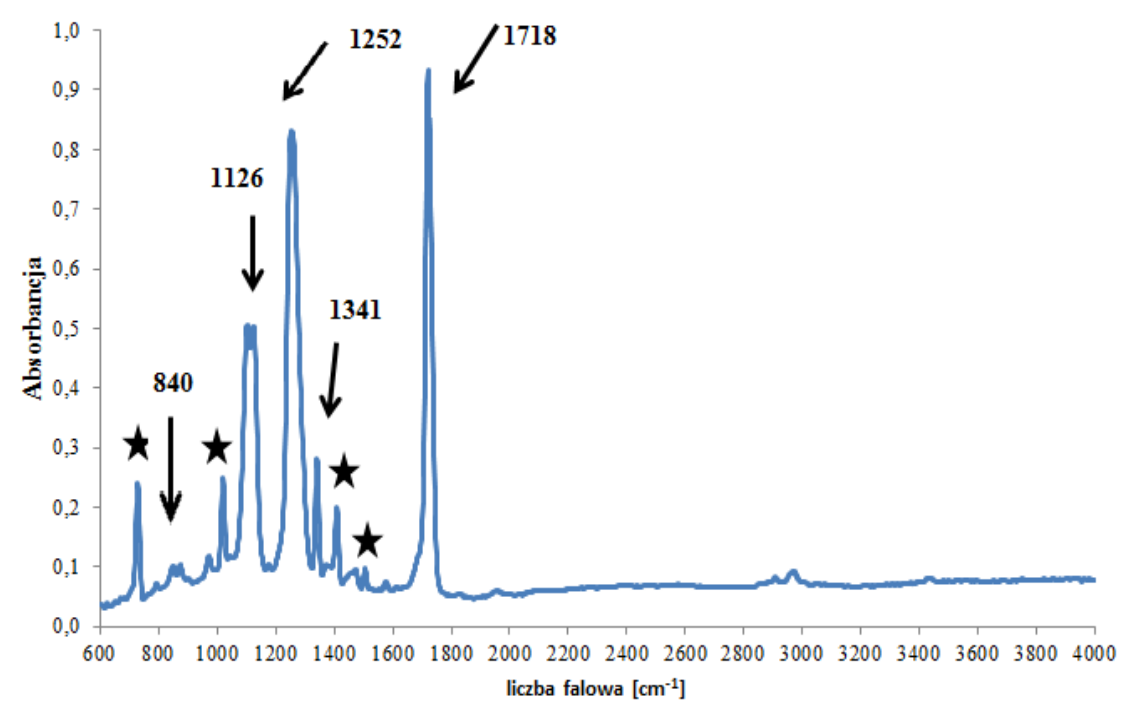

Figure 3a. Infrared spectrum of polyester backing type $\mathrm{C} 1$

- ring compounds 


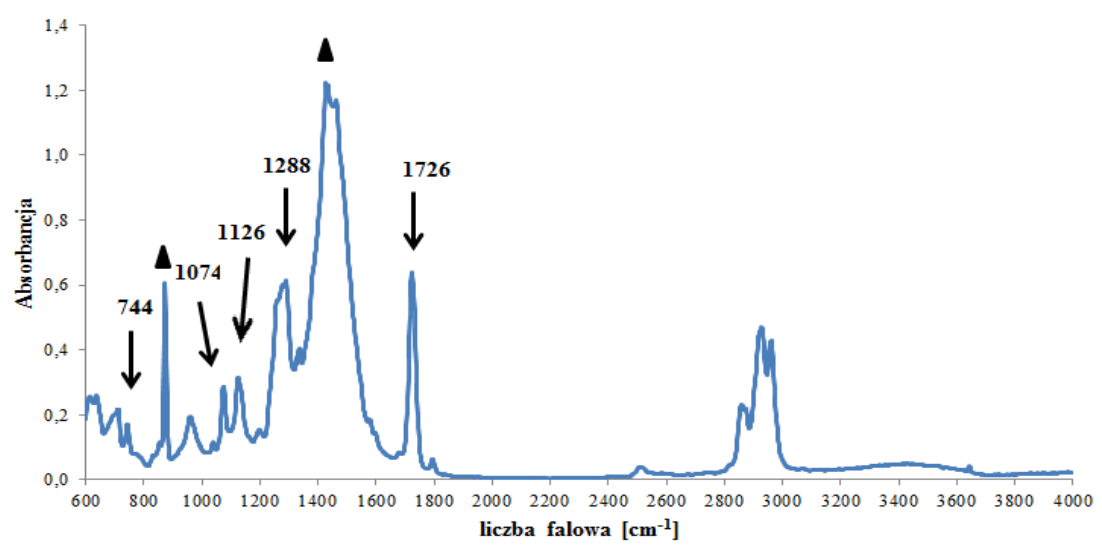

Figure 3b. Infrared spectrum of polyester backing type $\mathrm{C} 2$

$\Delta$ - carbonates.

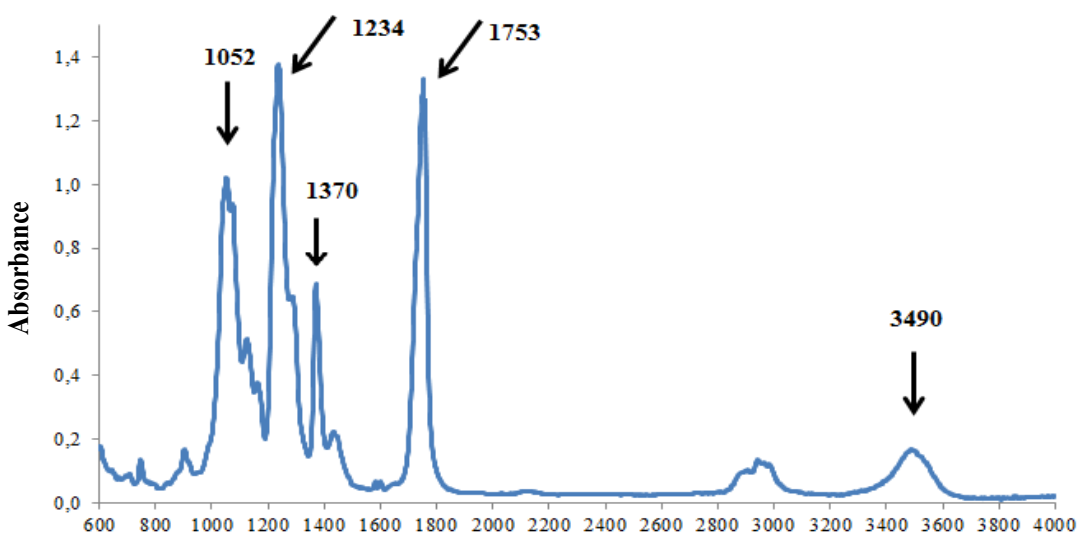

Wavenumber $\left[\mathrm{cm}^{-1}\right]$

Figure 4. Infrared spectrum of acetocellulose backing.

Table 4. Characteristic absorption bands of polymers visible in IR spectra of glues.

\begin{tabular}{|c|c|c|c|}
\hline Chemical compound & Absorption band & Assignment & Numer of samples \\
\hline \multirow[t]{6}{*}{ polyacrylate } & $1165 \mathrm{~cm}^{-1}$ & -C-O-C stretching symmetricalvibrations & \multirow[t]{6}{*}{25} \\
\hline & $1240-1265 \mathrm{~cm}^{-1}$ & -C-O-C stretching asymmetrical vibrations & \\
\hline & $1380 \mathrm{~cm}^{-1}$ & $\mathrm{CH}_{2}$ vibration & \\
\hline & $1450 \mathrm{~cm}^{-1}$ & $\mathrm{CH}_{3}$ vibration & \\
\hline & $1730 \mathrm{~cm}^{-1}$ & $-\mathrm{C}=\mathrm{O}$ stretching vibration & \\
\hline & $2240 \mathrm{~cm}^{-1}$ very weak & $-\mathrm{C} \equiv \mathrm{N}$ stretching vibration & \\
\hline \multirow[t]{5}{*}{ natural rubber } & $833 \mathrm{~cm}^{-1}$ & $=\mathrm{C}-\mathrm{H}$ deformation vibrations & \multirow[t]{5}{*}{15} \\
\hline & $1379 \mathrm{~cm}^{-1}$ & $\mathrm{CH}_{3}$ deformation vibrations & \\
\hline & $1451 \mathrm{~cm}^{-1}$ & $\mathrm{CH}_{2}$ deformation vibrations & \\
\hline & $1667 \mathrm{~cm}^{-1}$ weak & $\mathrm{C}=\mathrm{C}$ stretching vibrations & \\
\hline & $\begin{array}{l}2855 \mathrm{~cm}^{-1} \\
2926 \mathrm{~cm}^{-1} \\
2964 \mathrm{~cm}-1\end{array}$ & $\mathrm{C}-\mathrm{H}$ stretching vibrations & \\
\hline \multirow[t]{5}{*}{ butadiene styrene rubber } & $\begin{array}{l}700 \mathrm{~cm}^{-1} \\
760 \mathrm{~cm}^{-1}\end{array}$ & $\mathrm{C} \mathrm{H}$ deformation vibrations in ring & \multirow[t]{5}{*}{4} \\
\hline & $\begin{array}{l}912 \mathrm{~cm}^{-1} \text { weak } \\
968 \mathrm{~cm}^{-1} \\
995 \mathrm{~cm}^{-1} \text { weak }\end{array}$ & $=\mathrm{C}-\mathrm{H}$ deformation vibrations in butadiene & \\
\hline & $\begin{array}{l}1380 \mathrm{~cm}^{-1} \\
1450 \mathrm{~cm}^{-1}\end{array}$ & $\mathrm{CH}_{3}$ deformation vibrations & \\
\hline & $1495 \mathrm{~cm}^{-1} 1603 \mathrm{~cm}^{-1}$ weak & ring vibrations & \\
\hline & $\begin{array}{l}2854 \mathrm{~cm}^{-1} \\
2925 \mathrm{~cm}^{-1}\end{array}$ & drganiarozciągające $\mathrm{C}-\mathrm{H}$ & \\
\hline \multirow[t]{5}{*}{ polyester } & $745 \mathrm{~cm}^{-1}$ & stretching vibrations from the aromatic ring & \multirow{5}{*}{4} \\
\hline & $1077 \mathrm{~cm}^{-1}$ & stretching vibrations $\mathrm{C}-\mathrm{O}$ in $\mathrm{O}-\mathrm{CH}_{2}$ & \\
\hline & $1125 \mathrm{~cm}^{-1}$ & stretching vibrations $\mathrm{C}-\mathrm{O}-\mathrm{C}$ & \\
\hline & $1285 \mathrm{~cm}^{-1}$ & stretching vibrations $\mathrm{C}-\mathrm{O}$ in $-\mathrm{O}-\mathrm{C}=\mathrm{O}$ & \\
\hline & $1726 \mathrm{~cm}^{-1}$ & stretching vibrations $\mathrm{C}=\mathrm{O}$ & \\
\hline
\end{tabular}




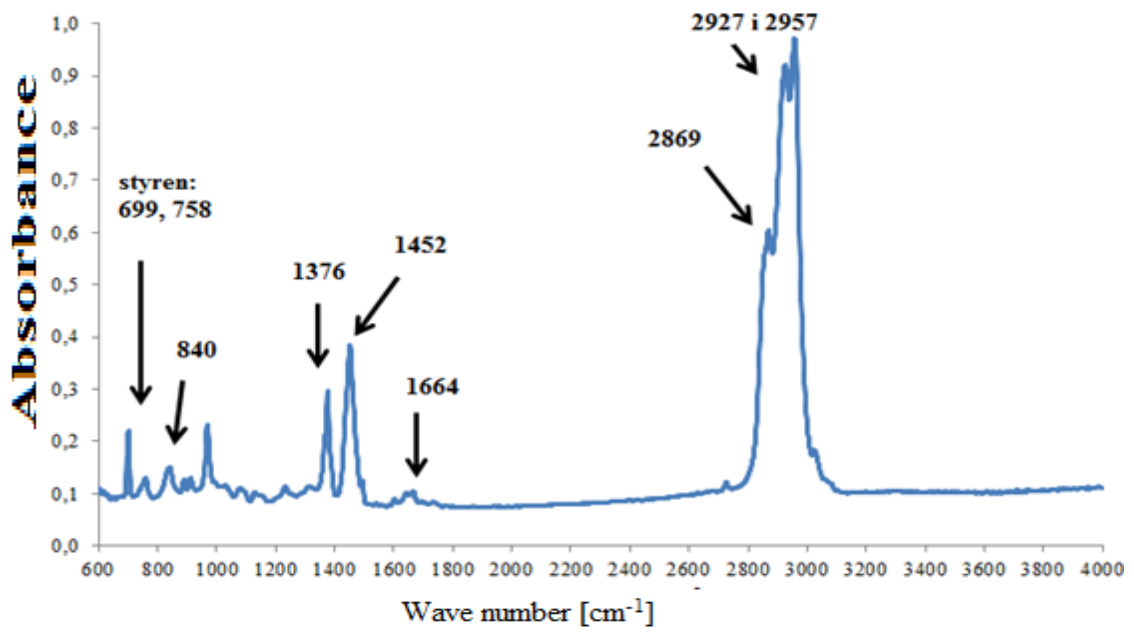

Figure 5a. Infrared spectrum of natural rubber glue modified with styrene.

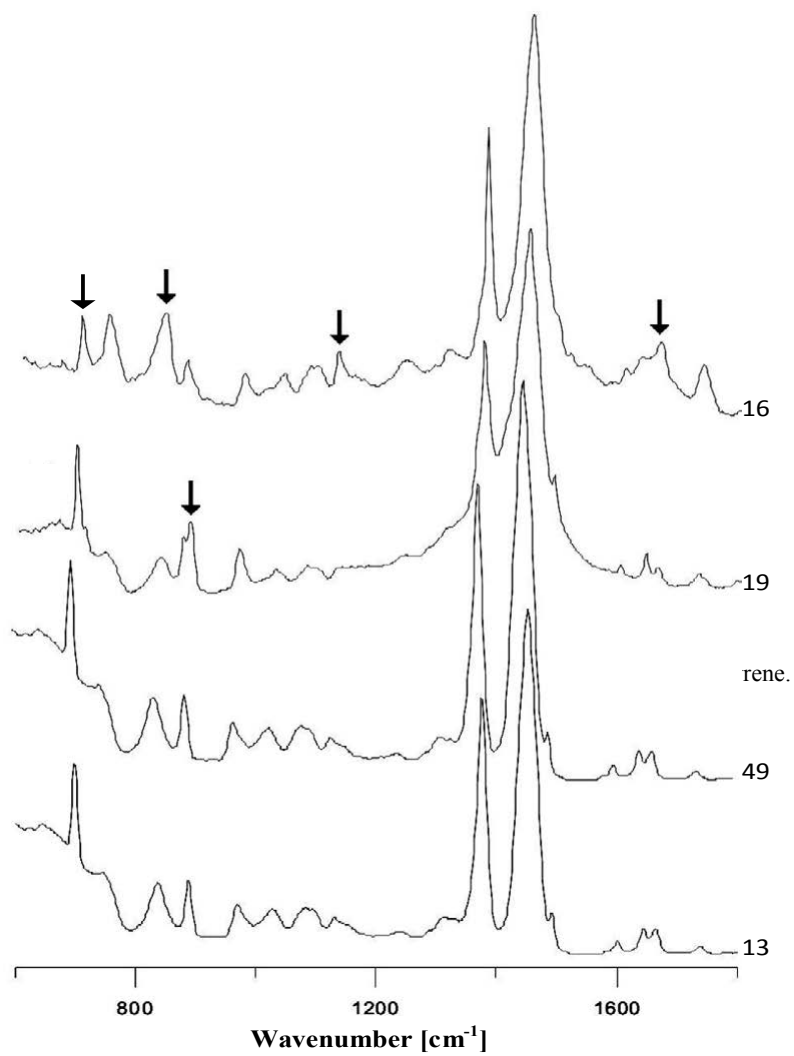

Figure 5b. Comparison of infrared spectra of different natural rubber glues (the main differences marked with arrows).

allowed four subgroups to be distinguished within this group of adhesives.

Acrylic adhesives (Figure 6a) most frequently contained methyl, ethyl, butyl or 2-ethylhexyl polyacrylates. The adhesives of 25 tapes that were classified into the group of acrylic adhesives were characterised by spectra that differed insignificantly in terms of location and intensity of bands, which may indicate their different chemical composition (Figure 6b).

However, in ester (Figure 7) and styrene-butadiene adhesives (Figure 8), only small differences were observed in the intensity of absorption bands, which was probably the result of slight differences in their chemical composition. But it was not possible to identify such components of the adhesives that influenced the shape of the IR spectra.

Comparing spectra of tape samples visually within the distinguished chemical classes separately for adhesives and for backings, it was ascertained that in most cases, the observed difference between spectra was sufficient to distinguish them. Furthermore, it is probable that differentiation of samples of very similar spectra would be possible with the application of a more sensitive analytical technique, i.e., gas chromatography of pyrolysis products of samples. For this method allows identification of components of low content in a studied sample. 


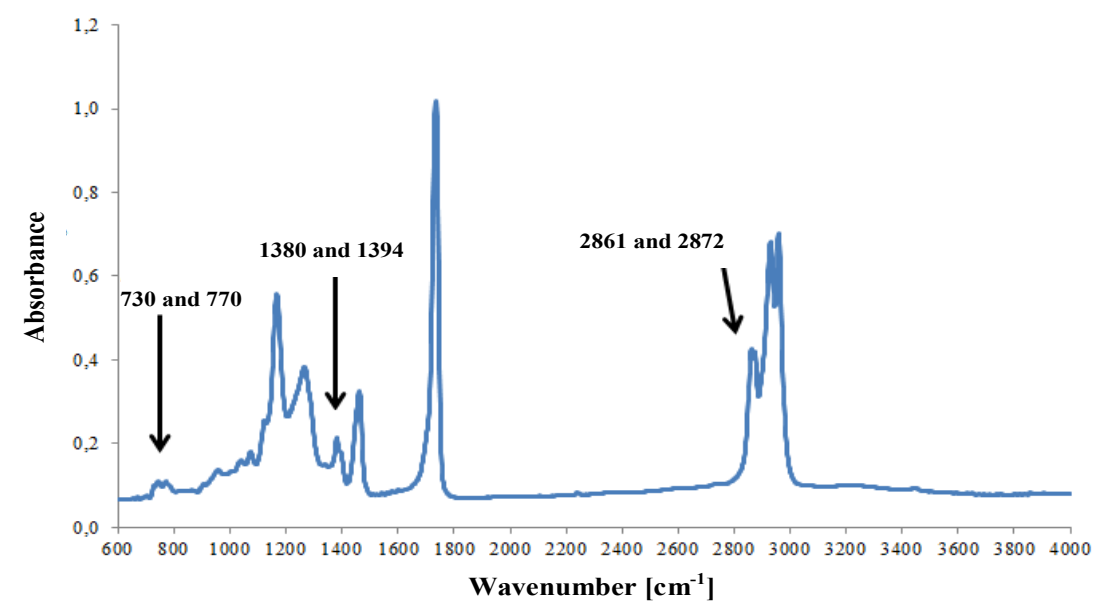

Figure 6a. Infrared spectrum of acrylic glue.

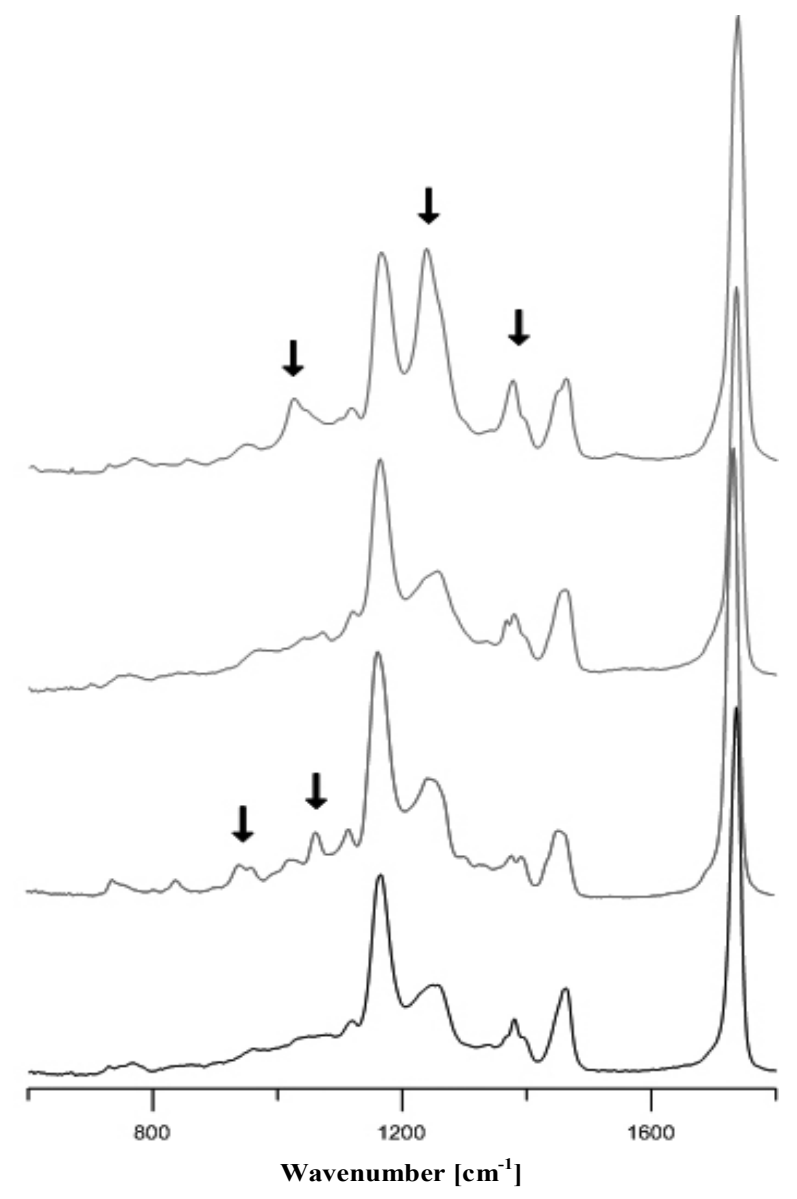

Figure 6b. Comparison of infrared spectra of different acrylic glues.

\section{Conclusions}

The results of the research show that infrared spectrometry is a valuable analytical technique in differentiating samples of adhesive tapes for forensic purposes. By providing information on polymer composition, IR spectrometry enables classification both of backings and adhesives into defined chemical classes. In the group of studied tapes, polyethylene and polypropylene backings and adhesives produced on the basis of synthetic isoprene rubber and acrylates predominate. Small differences in the chemical composition observed within a given class are the result of the presence of additives, e.g., fillers (carbonates and silicates) or plasticizers (phthalates), and also the technological process. The influence of the thin separating layer and the primer present in the tape is negligible. As these layers were not visible under the microscope at a magnification of $150 \mathrm{x}$, they were not initially separated from the backing and the adhesive but studied together with them. Due to their 


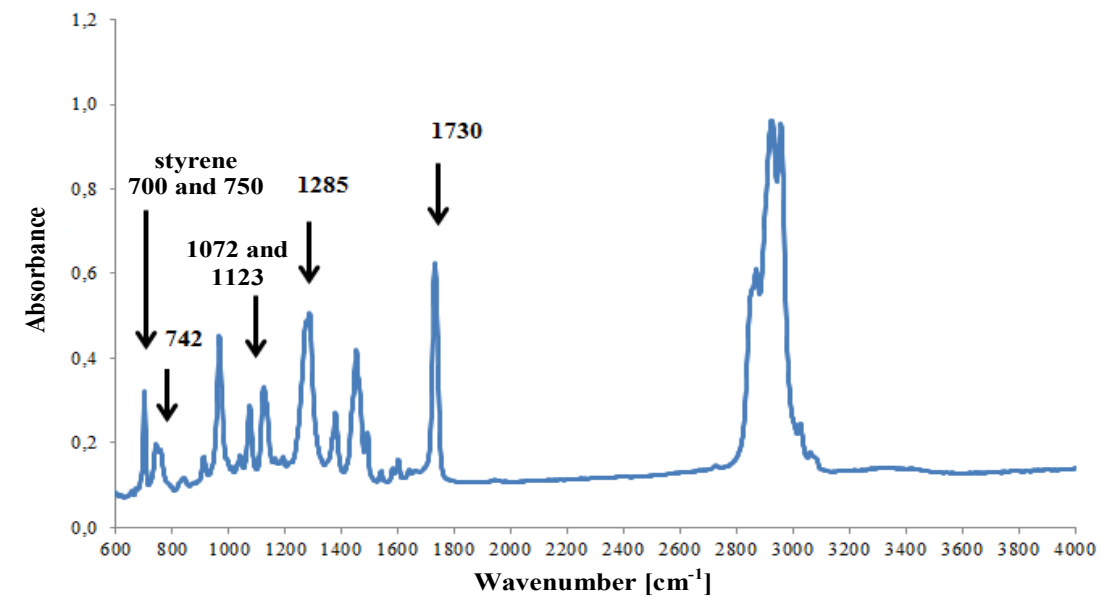

Figure 7. Infrared spectrum of polyester glue modified with styrene.

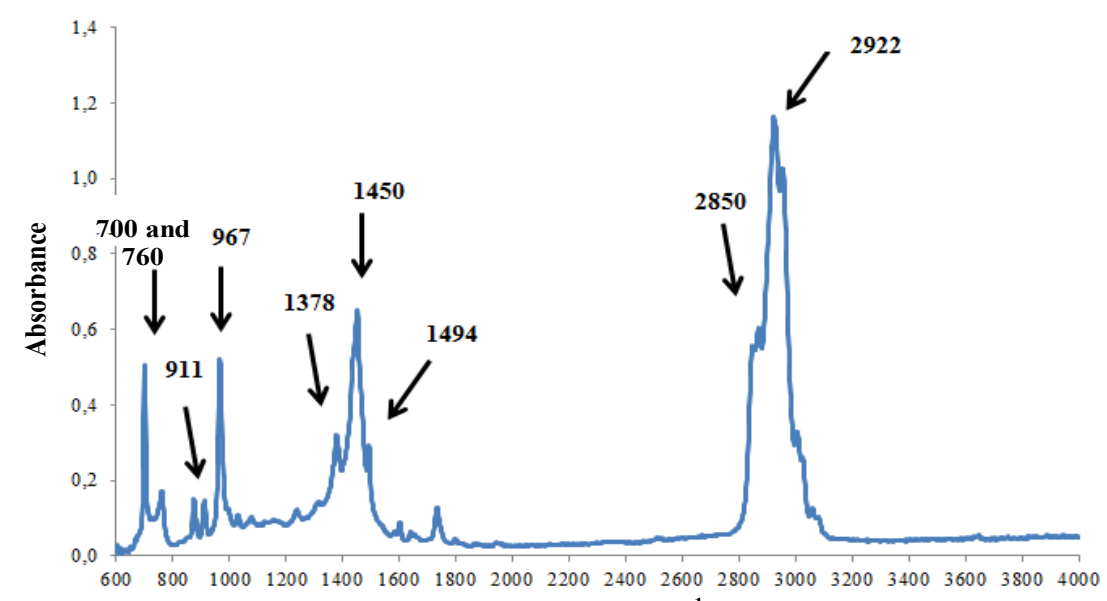

Wavenumber $\left[\mathrm{cm}^{-1}\right]$

Figure 8. Infrared spectrum of synthetic rubber glue modified with styrene

low content in the tape, the influence of these components is small. Taking into account the fact that a tape is composed both of a backing and an adhesive, it sometimes happens that compared tapes contain the same backing but different adhesives or the same adhesive, on different backings. Thus, there is greater possibility of differentiating tapes for forensic purposes. Additionally, application of another more sensitive analytical method, e.g., pyrolysis gas chromatography, enabling detections of subtle differences in chemical composition could help in further differentiation of adhesive tape samples belonging to the same chemical class of backings or glues.

The author declares that there is no conflict of interest regarding the publication of this paper.

\section{Acknowledgement}

The author would like to express her gratefulness to Mrs Sabina Nowińska for help with gathering a part of IR spectra of the studied material.

The research was financially supported by the Institute of Forensic Research, Poland, within the project no. II/K, 2009-2012.

\section{References}

1. Goodpaster JV, Sturdevant AB, Andrews KL, Briley EM, Brun-Conti L (2007)
Identification and comparison of electrical tapes using instrumental and statistical techniques: I Microscopic surface texture and elemental composition.J Forensic Sci 52: 610-629.

2. Blackledge RD (1992) Application of Pyrolysis Gas Chromatography in Forensic Science. Forensic Sci Rev 4: 1-16.[Crossref]

3. Kumooka Y (2006) Analysis of deteriorated rubber-based pressure sensitive adhesive by pyrolysis-gas chromatography/mass spectrometry and attenuated total reflectance Fourier transform infrared spectrometry. Forensic Sci Int 163: 132-137.

4. Williams ER, Munson TO (1988) The comparison of black polyvinylchloride (PCV) tapes by pyrolysis gas chromatography. Journal of Forensic Sciences 33: 1163-1170.

5. Dobney AM, Wiarda W, de Joode P,van der Peij GJ (2001) Elemental comparison of packing tapes using HR ICP/MS. Problems of Forensic Sciences XVII 275-287.

6. Dobney AM, Wiarda W, de Joode P, van der Peijl GJ (2002) Sector field ICP-MS applied to the forensic analysis of commercially available adhesive packaging tapes. Journal of Analytical Atomic Spectrometry 17: 478-484.

7. Ninomiya T, Nomura S, Taniguchi K, Ikeda S (1995) Applications of a glazing incidence X-ray fluorescence analysis to forensic samples.Analytical Sciences 11: 489-494.

8. Kumooka Y (2009) Hierarchical cluster analysis as tool for preliminary discrimination of ATR-FT-IR spectra of OPP acrylic and rubber-based adhesives, Forensic Sci Int 189: 104-110.

9. Merrill RA, Bartick EG (2000) Analysis of pressure sensitive adhesive tape: I. Evaluation of infrared ATR accessory advances J Forensic Sci 45: 93-98. [Crossref]

10. Zieba-Palus J, Augustynek A (2011) Effective differentiation of adhesive tapes by 
the use of infrared spectroscopy and pyrolytic-gas chromatography for criminalistic purposes,Problems of Forensic Sciences 86: 103-113.

11. Nakamura S, Takino M, Daishima S (2000) Analysis of pressure sensitive adhesives by GC/MS and GC/AED with temperature and programmable pyrolyser, Analytical Sciences 16: 627-631.

12. Kumooka Y (2010) Classification of OPP adhesive tapes according to MALDI mass spectra of adhesives. Forensic Sci Int 197: 75-79.[Crossref]

13. Sakayanagi M, Konda Y, Watanabe K, Harigaya Y (2003) Identification of pressure- sensitive adhesive polypropylene tape. J Forensic Sci 48: 68-76. [Crossref]

14. Zieba-Palus J, Kowalski R, Nowinska S (2016) Aplication of infrared spectroscopy and pyrolysis gas chromatography for characterisation of adhesive tapes. $J$ Molecular Struct1126: 232-239.

15. Pahl A (1996) Identification of adhesives in adhesive tapes. Kleben Dichten 41: 28-31.

16. Mehltretter AH, Bradley MJ, Wright DM (2011) Analysis and discrimination of electrical tapes: Part I. Adhesives. J Forensic Sci 56: 82-94.[Crossref]

Copyright: @2017 Zięba-Palus J. This is an open-access article distributed under the terms of the Creative Commons Attribution License, which permits unrestricted use, distribution, and reproduction in any medium, provided the original author and source are credited. 